Final pre-publication version. This article is now published as: King, A and Cronin, A (2016) "Bonds, Bridges and Ties: Appling Social Capital Theory to LGBT People's Housing Concerns Later in Life", Quality in Ageing and Older Adults, 17(1): 16-25.

\title{
Bonds, Bridges and Ties: Applying Social Capital Theory to LGBT People's Housing Concerns Later in Life
}

\section{Introduction}

The aim of this short article is to provide a critical, theoretical, intervention and discussion piece regarding housing concerns for lesbian, gay, bisexual and transgender (LGBT) ${ }^{\mathrm{i}}$ people as they get older. Specifically, the article argues for the significance of using social capital theory (SCT) in this debate ${ }^{\mathrm{ii}}$. Studies consistently suggest that older LGBT people have a series of concerns about housing later in life, whether related to their existing home or entering specialist sheltered housing or residential care. We will argue here that these concerns are not simply practical issues, important as they might be, but can be related to ideas about social connectedness, networks, trust and above all social divisions and power relations.

We begin, therefore, with a short exegesis of social capital theory (SCT), particularly as it has been developed in the work of Robert Putnam and Pierre Bourdieu. We outline some key conceptual aspects of SCT, including bonding, bridging and horizontal and vertical ties, but also discuss some important differences between Putnam's and Bourdieu's accounts, principally concerning power and inequality. Subsequently, we explore some key concerns to have emerged from studies of housing amongst older LGBT people. In the third section, theoretical applications and implications, we frame these concerns around SCT, thereby illustrating how SCT is useful for thinking further about them. We also consider some ramifications for future research, policy and practice regarding housing and older LGBT people.

\section{Social Capital Theory (SCT)}

The concept of social capital has been used to explore the nature, role and value of social networks, connections and forms of community (Portes, 1998). It has been developed by scholars from a range of disciplines and has been championed as a way to explore and resolve a wide variety of social issues and problems, including: health and well-being, crime, education and economic growth (Field, 2008). The theorisation of social capital, however, is primarily related to three writers, James Coleman, Robert Putnam and Pierre Bourdieu (ibid.). 
Final pre-publication version. This article is now published as: King, A and Cronin, A (2016) "Bonds, Bridges and Ties: Appling Social Capital Theory to LGBT People's Housing Concerns Later in Life", Quality in Ageing and Older Adults, 17(1): 16-25.

Our discussion here will draw on the work of Putnam and Bourdieu because, arguably, they have had the greatest impact in debates about the concept over the past twenty years.

Initially Putnam (1993: 167) stated that social capital "refers to features of social organisation, such as trust, norms and networks, that can improve the efficiency of society by facilitating coordinated actions", but later amended this to emphasise "connections among individuals - social networks and the norms of reciprocity and trust that arise from them" (Putnam, 2000: 19). In effect, Putnam argues that social capital is how connections and the trust and reciprocity that follow from them accrue value to individuals and communities. Conversely, lacking social capital is disadvantageous, leading to isolation (for individuals) and a breakdown in social bonds at a communal level.

Putnam $(1993$; 2000) differentiated two types of social capital: bonding and bridging. Bonding social capital refers to connections and relationships within groups, it is inclusive and homogenous. This type of social capital underpins norms of reciprocity, solidarity and loyalty amongst groups. Bridging social capital comes from the connections and relationships that link different groups and is less inclusive, more heterogeneous. Bridging helps to create broader alliances, disseminate information and acts in Putnam's (2000: 23) words as "a sociological WD-40", aiding social action, wider social relationships and connections. Putnam asserts that, in effect, people tend to belong to groups that both bond and bridge, creating connections amongst those perceived to be similar and those different.

Putnam (1993) and others (Agnitsch et al., 2006) have also identified horizontal and vertical associations, or ties, within and between groups. Horizontal ties connect those in similar positions: for instance, friends, community members. Vertical ties connect those of dissimilar positions: for instance, those in hierarchical relationships, often in bridging forms, such as bank manager/client, care giver/care receiver etc. Vertical ties create in-group cohesion; horizontal ties enable across-group connections.

Whilst Putnam's ideas have been highly influential, they have also been critiqued for being social conservative and normative (for a good discussion see Field, 2008). There is a tendency for Putnam's ideas to reinforce the existing status quo and occlude differences of power and (in)equality. Conversely, Pierre Bourdieu's work on social capital, to which we now turn, emphasises how social capital creates differences and inequalities. 
Final pre-publication version. This article is now published as: King, A and Cronin, A (2016) "Bonds, Bridges and Ties: Appling Social Capital Theory to LGBT People's Housing Concerns Later in Life", Quality in Ageing and Older Adults, 17(1): 16-25.

In contrast to Putnam, whose ideas primarily concerned US society, Bourdieu developed his from observing social reproduction amongst Algerian tribespeople and later social distinctions in French society (Bourdieu, 1984; 1989; Field, 2008). Bourdieu's notion of social capital emphasises the relationship between connections and socially structured forms of power; this enables individuals within social groups to attain and retain positions of privilege over others. Social capital, the resources and value that accrues from social connections and networks, is related to other forms of capital, such as cultural (education and knowledge) and economic (monetary). In effect, these capitals are used to create and maintain social power and distinction. Bourdieu argued that elite groups do not maintain their social dominance through economics and knowledge alone, but through social connections acquired through knowing the right people, going to the right school/club, then getting the best job. To put it bluntly, social capital reproduces wider inequality.

What Bourdieu gives us is a more critical understanding of social capital; rather than emphasising its 'social goods', Bourdieu shows us how it serves vested interests and creates 'social bads'. Social connections matter because they are related to social power. Like Putnam, Bourdieu's work has been subject to much criticism, ostensibly that his work on social capital has focused too heavily on the recreation of hierarchy and social structure and not enough on social change (Portes, 1998; Field, 2008). However, others reject this criticism (Skeggs, 2004) and argue that all individuals and groups can accrue social capital, albeit on an unequal footing.

SCT therefore gives us a rich theoretical toolbox for examining social connections, networks, issues of trust and reciprocity and how these are maintained and change. It can be applied to any situation or issue where human relationships are significant. Before explaining how this helps us to understand LGBT people's housing later in life, we briefly consider a series of concerns that have been identified as problems in this area.

\section{LGBT people's concerns about housing later in life}

There are a growing number of studies that document areas of concern that older LGBT people have in relation to housing later in life. It should be noted, however, that the vast majority of these studies focus on the experiences of older lesbian, gay and bisexual people with older trans people's housing concerns and issues less well documented, especially in the UK. In addition, there remains an element of bi-invisibility (Jones, 2011) in studies of ageing 
Final pre-publication version. This article is now published as: King, A and Cronin, A (2016) "Bonds, Bridges and Ties: Appling Social Capital Theory to LGBT People's Housing Concerns Later in Life", Quality in Ageing and Older Adults, 17(1): 16-25.

sexualities, such that bi people are included in the acronym LGB without adequate consideration of their unique experiences when compared to lesbian and gay people. We reflect critically on these important issues in relation to applying SCT to older LGBT housing throughout this article. Here, we focus on three key themes to emerge from the existing literature: concerns about ageing in place; concerns about moving into specialist housing; and intersections.

\section{Concerns about ageing in place}

Studies show that the home, or domestic environment, is an important space for older LGBT people; a refuge from a world in which normative (hetero)sexuality and gender pervade (Addis et al., 2009). Yet older LGBT people have concerns regarding how their existing domestic environment might change as they age, so called 'ageing in place'. For instance, older LGBT people have concerns about a range of service providers they might have to let into their homes, such as health and care staff, domestic workers, even tradespeople who they might need to repair or maintain their home as they become less able. This may lead older LGB adults to 'desexualise' their home, whereby they divest it of any 'traces' or signifiers of their sexualities (Fannin et al., 2008; Cronin et al., 2011), whilst older trans people may have particular concerns that people coming into their home may result in unwanted questioning of their gender identity (Witten, 2009). For instance, older trans people may have additional fears that may arise from personal items, such as photographs displayed in their home, as well as concerns about personal care. In all of the cases noted above, questions of trust with those entering the home may be paramount and being able to form bonds with these 'others' will affect how the home continues to be experienced.

Ageing in place is also important in relation to retaining connections with a wider community of LGBT friends and/or 'families of choice' (SAGE, 2012; Cronin and King, 2014). Such networks and supports have been shown to be significant in terms of quality of life, well-being and coping with prejudice and stigma, although staying in place when LGBT friends and family leave an area can be equally challenging, especially in relation to social isolation (Shippy et al., 2004; Brennan-Ing et al., 2013; Orel, 2014). Hence, part of older LGBT people's concerns about housing later in life relates to the potential for social dislocation; that is, the fragmentation of social networks (Barrett et al., 2014). Not ageing in place has the potential to disrupt existing social connections. Whilst this could apply to 
Final pre-publication version. This article is now published as: King, A and Cronin, A (2016) "Bonds, Bridges and Ties: Appling Social Capital Theory to LGBT People's Housing Concerns Later in Life", Quality in Ageing and Older Adults, 17(1): 16-25.

anyone, regardless of sexuality or gender identity, it is arguably magnified for older LGBT people since the loss of connections that may have sustained them and provided forms of resilience and empowerment is effectively a loss of social as well as individual power (Addis et al., 2009).

\section{Concerns about moving into specialist housing}

Evidence from surveys conducted in the US, Australia and the UK (Hubbard and Rossington, 1995; Johnson et al., 2005; Metlife, 2010; GRAI and Curtin Health Innovation Research Institute, 2010; Guasp, 2011), in addition to more qualitative studies (Davies et al., 2006; Knocker, 2006; Phillips and Marks, 2006) suggests that LGBT people have heightened concerns about moving into specialist housing, such as residential care or retirement complexes, later in life. In research conducted for Stonewall UK (Guasp, 2011), 70\% of the older LGB people surveyed felt they would not be able to maintain an acceptable level of privacy in a care home setting, in contrast to $61 \%$ of the heterosexual people surveyed. Indeed, these spaces are perceived to be heteronormative, the assumption that all people are heterosexual (Tolley and Ranzijn, 2006) and also cisnormative, the assumption that all people are cissexual; that is, a person's understanding of their gender aligns directly with the sex they were assigned at birth (Bauer et al., 2009). Such misrecognition can lead to an erasure of self, a concomitant lowering of self-worth, an increase in passing strategies, the failure to meet specific health and social care needs and inevitably creates a climate for more overt discrimination (Jackson et al., 2008; Musingarimi, 2008; Stein et al., 2010; SAGE, 2012).

Discrimination in residential and care home settings can be institutional, related to how the specialist housing is organised and operated, interpersonal in terms of actual experiences older LGBT people have with service providers or fellow residents (Dickey, 2012; Grossman et al., 2014) or the result of a lack of understanding or acceptance on the part of staff (Hinrichs and Vacha-Haase, 2010). Discrimination can also be manifested at an intrapsychic level, such as LGBT people's own thoughts and fears, based on expectations or anecdotal reports they may have heard from others (Sullivan, 2013). The effect, however, is much the same: older LGBT people are overwhelmingly concerned about and many want to avoid mainstream older people's housing (Neville and Henrickson, 2010; Westwood, 2015). In these cases, sexuality and gender identity act as barriers to forming social connections and 
Final pre-publication version. This article is now published as: King, A and Cronin, A (2016) "Bonds, Bridges and Ties: Appling Social Capital Theory to LGBT People's Housing Concerns Later in Life", Quality in Ageing and Older Adults, 17(1): 16-25.

relationship of trust and reciprocity in these settings, with the potential to have a detrimental effect on well-being.

\section{Concerning intersections}

In spite of the above discussion, the housing concerns and indeed preferences amongst and between older LGBT people are multiple and varied. Indeed, research concerning older LGBT people suggests intersectional differences are important to consider more broadly (Purdie-Vaughns and Eibach, 2008; Crisp, 2014; Cronin and King, 2014) and there are a number of important intersectional differences especially significant in relation to housing.

Firstly, differences have been reported relating to gender and sexual orientation; with lesbians and bisexual women and gay and bisexual men reporting both different experiences and preferences in what sort of housing they would like (Barker et al., 2012; Traies, 2012). Lesbian and bisexual women express greater preferences for gender and sexuality specific housing, compared to gay and bisexual men (Westwood, 2015).

Secondly, trans people do not necessarily want LGBT provision. Research suggests that some trans people regard such an option as primarily about sexuality, obscuring gender identity and aware of transphobia amongst lesbian, gay and/or bisexual communities (Witten, 2009; SAGE, 2012).

Thirdly, intersections of social class, ethnicity and geography are likely to shape decisions, choices and options (Comerford et al., 2004; Calasanti and Kiecolt, 2007; PurdieVaughns and Eibach, 2008; Stone and Ward, 2011; Fisher et al., 2013). In our own research (Cronin and King, 2014), for instance, we demonstrated how the ability to make retirement choices, which included those related to housing, were structured by intersections of gender, sexuality and social class. Meanwhile, Witten (2009) has shown that housing decisions amongst older trans people in the US are constrained by the intersection of poverty and a lack of access to supportive social networks, particularly for trans women of colour. Hence, sexuality and gender identity should not necessarily be viewed as preeminent in relation to housing decisions made by older LGBT people; a lens through which all decisions are made. Other sources of social identity, division and inequality remain crucial too.

Fourthly, there are concerns with the oft expressed division between LGBT-specific and LGBT-friendly housing options (Lucco, 1987; Gabbay and Wahler, 2002), since this 
Final pre-publication version. This article is now published as: King, A and Cronin, A (2016) "Bonds, Bridges and Ties: Appling Social Capital Theory to LGBT People's Housing Concerns Later in Life", Quality in Ageing and Older Adults, 17(1): 16-25.

binary obscures other possibilities and ways of constructing connections and networks. This can include intergenerational (Hamburger, 1997; Vaccaro, 2009) and co-operative housing (Traies, 2012; Carr and Ross, 2013) and those that might emerge from non-institutionalised sources e.g. informal decisions amongst groups of friends (Westwood, 2013).

Finally, questions of hope, celebration and empowerment should not be overlooked or obscured by a discourse of constraint and disempowerment (Cronin and King, 2010; King, forthcoming 2016). Not all older LGBT people may perceive or experience housing as problematic and as we noted earlier, this may be correlated to social class and gender, in particular: some white, middle-class gay men may have more choice and fewer stressors, but not all.

We reflect on the implications of the intersections we have discussed here in the following theoretical applications section, but it should be noted that what intersections imply is that thinking about connections and networks in relation to older LGBT people and housing, means being aware of intra-group differences and diversities.

\section{Theoretical applications and implications}

What is obvious to us is that it is not bricks and mortar that older LGBT people are concerned with in relation to housing later in life per se, but the social relationships that those structures contain. Housing is a space where social networks, connections, questions of trust and reciprocity converge; in short, a site concerning questions of social capital. In this section of the article we want to draw together the preceding two sections to illustrate the utility of applying SCT to older LGBT people's concerns about housing more broadly.

As we indicated above, concerns about moving house include those related to a loss or change in social connections - in effect, these are changes primarily in bonding social capital. To lose this form of social capital as one ages is to risk becoming socially isolated from others like oneself, with consequential effects on well-being (Field, 2008). Dislocation from other LGBT people may occur if one has to relocate. Moving into residential care or a retirement complex creates a potential break in relationships with LGBT friends and networks. In effect, the horizontal ties and social bonds are potentially disrupted and broken. Furthermore, being frightened of what staff or other residents in a care home or housing complex setting might say about a signifier of gender identity or sexuality may lead to 
Final pre-publication version. This article is now published as: King, A and Cronin, A (2016) "Bonds, Bridges and Ties: Appling Social Capital Theory to LGBT People's Housing Concerns Later in Life", Quality in Ageing and Older Adults, 17(1): 16-25.

hiding/passing, a 'fitting in'. This is a loss of identity, which, symbolically, creates a loss of bonding social capital - to lose one's identity is to potentially lose one's sense of connection to others who one wishes to be associated with. The ability for keeping bonds of reciprocity and trust is therefore decreased. Similarly, having to divest one's home of traces of sexuality or gender identity, if one ages in place, but is reliant on formal supports, can also create a loss of identity. There are serious implications here for the horizontal and vertical ties of bridging social capital too and particularly the norms of reciprocity and trust that Putnam, in particular, believes they are built upon. Hence the value of Bourdieu's ideas on the sustaining of inequalities via social capital - having and maintaining a set of connections that differ from the (hetero and cis)normative, whilst providing resources for self-identity, may be challenging when domestic circumstances change. The normative structure impinges on one's agency; one's ability to be oneself and to connect to others.

Putnam's work indicates to us that bridging social capital and vertical ties are, indeed, clearly important when an older LGBT person is utilising or forming connections with service providers; whether they are providing services for one to age in place, or a new domestic environment. Being able to negotiate these relationships will affect well-being. Yet, as the evidence we presented above indicates, service providers may be ignorant (at best) and discriminatory in how they deal with older LGBT people, particularly so with bi and trans people. Similarly, forming bridging social capital, but more horizontal ties, with other heterosexual and/or cisgender residents in care homes or a housing complex are important, but again may be affected by their attitudes and behaviours (Donaldson et al., 2014). In effect, heteronormativity and cisnormativity can distort the development of bridging social capital, ties and subsequently affect well-being.

We also noted above, however, that intersections are especially important in this discussion. There are differences and inequalities within and between older lesbian, gay, bisexual and trans people. Some older LGBT people may have developed forms of resilience across their life course; a result of dealing with discrimination over a lifetime, that may make them particularly adept at dealing with these challenges (Butler, 2004; Witten, 2014). Wider LGBT social networks may indeed form barriers to discrimination. Yet knowing how to 'play the game' to develop and use social capital (Bourdieu, 1989) is not evenly distributed, even amongst LGBT populations. There are differences in access to social networks and connections amongst and between LGBT people; hence, white, middle-class cisgendered gay 
Final pre-publication version. This article is now published as: King, A and Cronin, A (2016) "Bonds, Bridges and Ties: Appling Social Capital Theory to LGBT People's Housing Concerns Later in Life", Quality in Ageing and Older Adults, 17(1): 16-25.

men who are embedded in a vibrant gay community may be able to negotiate housing travails more easily and with better outcomes than others. This is because their 'stocks' of social capital and its connection with other forms of capital, such as the economic and the cultural, may protect them in ways that others may lack. Education and knowledge, a key feature of Bourdieu's notion of cultural capital, which affects the development and maintenance of social capital, is also significant here. To give one example, 'personalisation', the ability of individuals to tailor and chose the services they use (Carr, 2010), may appear to be a way for older LGBT people to ensure they receive appropriate and acceptable support/care/services. However, knowing how to navigate the system is itself socially patterned, with those with greater levels of cultural and social capital advantaged. Furthermore, bisexual and trans people are also affected by bi and transphobia from older lesbian and gay people as well as heterosexual and cisgendered people. Thus a more nuanced understanding of differences within a possibly mythic 'LGBT community' needs further exploration. In this respect, social isolation is not only about being isolated from others, whether LGBT or not, but from being able to build connections through the use of knowledge and money, alongside sexual and gender identity. Hence, Bourdieu's SCT adds, in our view, a more refined understanding of difference and power to understandings of older LGBT housing which Putnam's more communitarian and conservative approach can obscure. It is not simply about creating bonds, bridges and ties, but who constructs them, in what ways and with whom that is also important.

There are, of course, numerous policy and practice interventions that seek to 'level the playing field' to address the effects of hetero and cis-norms, which will have an effect on social capital. Equality legislation is perhaps an obvious one, apparently protecting older LGBT people from overt discrimination at the hands of service providers; similarly, programmes of 'cultural competence' and training programmes working with service providers and others may help (Clover, 2006; Knochel et al., 2012; Bauer et al., 2014). This is particularly the case for increasing understanding of trans people's lives amongst housing providers, which is especially lacking (SAGE, 2012). Increasing understanding, reducing prejudice and harm may facilitate trust and reciprocity and therefore build bridging social capital, in particular. Meanwhile, finding ways to support older LGBT people's existing social networks and create new ones are important if older LGBT people are not to be isolated: for example, we have heard of some care homes celebrating LGBT History Month 
Final pre-publication version. This article is now published as: King, A and Cronin, A (2016) "Bonds, Bridges and Ties: Appling Social Capital Theory to LGBT People's Housing Concerns Later in Life", Quality in Ageing and Older Adults, 17(1): 16-25.

or ensuring that LGBT people are represented in institutional documentation. Yet as shown elsewhere (Colgan and McKearney, 2012; King, 2015), such interventions are also affected by issues of the social capital of individuals within organisations; all too often such interventions rely on the emotional and symbolic labour of LGBT staff and the forms of bonding and bridging social capital that they are able to develop with others that can be applied to their work. To provide an example from a project we conducted with service providers (King, 2015), it was reported to us that LGBT staff are often asked to take on additional roles, being 'the LGBT champion' and draw on their own LGBT networks and connections to support such activities. Without this, such initiatives may be less successful, or less likely to come to fruition.

At a more conceptual level, we are also aware of problems with utilising SCT in relation to older LGBT people, as noted previously by ourselves and others (Hughes and Kentlyn, 2011; Cronin and King, 2014). Principally, SCT has been theorised in heteronormative and cisnormative terms. Hence, it runs the risk of ignoring differences in connectedness of LGBT people and differences that exist within and between older LGBT on the grounds of sexuality and gender identity - as we have noted throughout this article, not all LGBT people are the same. Our suggestion, therefore, is to think about older LGBT people's social capital as similar to, yet containing fundamental differences with, older heterosexual and/or cisgender people. Initiatives, like the ones outlined in the preceding paragraph, need to look at ways of working with and extending social capital, not as a problem, but as a solution. Older LGBT housing provides a forum for thinking these issues through; a discursive as well as material space for addressing and accepting difference and challenging prejudice.

\section{Conclusion}

Social capital matters. It matters because connections, networks and relations of trust and reciprocity are central to well-being. It has been our argument in this short article that examining older LGBT people's concerns about housing through the lens of social capital theory (SCT) is useful because it avoids an overly individualistic view of this topic; SCT is, unsurprisingly, resolutely social. Applying SCT as developed by Putnam and Bourdieu to the housing concerns of older LGBT people enables us to conceptualise these as a set of connected and relational conditions and lived experiences, not only private and practical ones. There are plenty of good suggestions about how to improve housing for older LGBT 
Final pre-publication version. This article is now published as: King, A and Cronin, A (2016) "Bonds, Bridges and Ties: Appling Social Capital Theory to LGBT People's Housing Concerns Later in Life", Quality in Ageing and Older Adults, 17(1): 16-25.

people, but in our view unless these are framed in a wider social context, they are in danger of missing the social structural and power dynamics at play, particularly the deleterious effects of heteronormativity and/or cisnormativity and how these relate to other intersectional inequalities. Indeed, housing is one arena, arguably institutions associated with health and medicine are others, where the 'social bads' associated with heteronormativity and cisnormativity are played out and can be magnified, but also challenged. Older LGBT people can lose social capital through actions associated with housing later in life, but they can also develop and extend it, although as we have indicated throughout, important inequalities and intersectional differences must be considered.

However, if we are to fully comprehend the significance of the relationship between social capital and housing for older LGBT people, more research is needed, particularly in the UK. It is for this reason that along with colleagues, we are currently undertaking a small pilot study 'SAFE Housing: Older LGBT Housing Later in Life', which is exploring older LGBT people's concerns, preferences and options about housing in two areas of England. But in doing so, we are contextualising these questions with older LGBT people's attitudes towards ageing, feelings about and connections with LGBT others and with wider society; in short, using ideas drawn from SCT and exploring intersectional differences in more detail. Indeed, a further strength of SCT is its use in making sense of research and 'SAFE Housing' is a first step in bringing together what to us are important and useful theoretical insights with empirical data.

\section{References}

Addis S, Davies M, Greene G, et al. (2009) The Health, Social Care and Housing Needs of Lesbian, Gay, Bisexual and Transgender Older People: A Review of the Literature. Health \& Social Care in the Community 17: 647-658.

Agnitsch K, Flora J and Ryan V. (2006) Bonding and Bridging Social Capital: The Interactive Effects on Community Action. Community Development 37: 36-51.

Barker M, Richards C, Jones R, et al. (2012) The Bisexuality Report - Bisexual inclusion in LGBT equality and diversity. Milton Keynes: Open University.

Barrett C, Whyte C, Comfort J, et al. (2014) Social connection, relationships and older lesbian and gay people. Sexual and Relationship Therapy 30: 131-142.

Bauer GR, Hammond R, Travers R, et al. (2009) "I Don't Think This Is Theoretical; This Is Our Lives": How Erasure Impacts Health Care for Transgender People. Journal of the Association of Nurses in AIDS Care 20: 348-361.

Bauer M, Fetherstonhaugh D, Tarzia L, et al. (2014) Supporting residents' expression of sexuality: the initial construction of a sexuality assessment tool for residential aged care facilities. Bmc Geriatrics 14: 1-6. 
Final pre-publication version. This article is now published as: King, A and Cronin, A (2016) "Bonds, Bridges and Ties: Appling Social Capital Theory to LGBT People's Housing Concerns Later in Life", Quality in Ageing and Older Adults, 17(1): 16-25.

Bourdieu P. (1984) Distinction: A Social Critique of the Judgement of Taste, London: Routledge and Keegan Paul.

Bourdieu P. (1989) Social Space and Symbolic Power. Sociological Theory 7: 14-25.

Brennan-Ing M, Seidel L, Larson B, et al. (2013) Social Care Networks and Older LGBT Adults: Challenges for the Future. Journal of Homosexuality 61: 21-52.

Butler SS. (2004) Gay, Lesbian, Bisexual and Transgender Elders: the Challenges and Resilience of this Marginalized Group. Journal of Human Behavior in the Social Environment 9: 25-44.

Calasanti TM and Kiecolt KJ. (2007) Diversity Among Late-Life Couples. Generations 31: $10-17$.

Carr S. (2010) Personalisation: A Rough Guide, London: Social Care Institute for Excellence.

Carr S and Ross P. (2013) Assessing Current and Future Housing and Support Options for Older LGB People. York: Joseph Rowntree Foundation.

Clover D. (2006) Overcoming Barriers for Older Gay Men in the Use of Health Services: A Qualitative Study of Growing Older, Sexuality and Health. Health Education Journal 65: 41-52.

Colgan F and McKearney A. (2012) Visibility and Voice in Organisations: Lesbian, Gay, Bisexual and Transgendered Employee Networks. Equality, Diversity and Inclusion: An International Journal 31: 359-378.

Comerford SA, Henson-Stroud MM, Sionainn C, et al. (2004) Crone Songs: Voices of Lesbian Elders on Aging in a Rural Environment. Affilia 19: 418-436.

Crisp C. (2014) White and Lesbian: Intersections of Privilege and Oppression. Journal of Lesbian Studies 18: 106-117.

Cronin A and King A. (2010) Power, Inequality and Identification: Exploring Diversity and Intersectionality amongst Older LGB Adults. Sociology 44: 876-892.

Cronin A and King A. (2014) Only Connect? Lesbian, Gay and Bisexual (LGB) Adults and Social Capital. Ageing and Society 34: 258-279.

Cronin A, Ward R, Pugh S, et al. (2011) Categories and their Consequences: Understanding and supporting the caring relationships of older lesbian, gay and bisexual people International Social Work 54: 421-435.

Davies M, Addis S, MacBride-Stewart S, et al. (2006) The Health, Social Care and Housing needs of Lesbian, Gay, Bisexual and Transgender older people: literature review. Cardiff: Centre for Health Sciences Research, Cardiff University

Dickey G. (2012) Survey of Homophobia: Views on Sexual Orientation From Certified Nurse Assistants Who Work in Long-Term Care. Research on Aging.

Donaldson WV, Asta EL and Vacha-Haase T. (2014) Attitudes of Heterosexual Assisted Living Residents Toward Gay and Lesbian Peers. Clinical Gerontologist 37: 167-189.

Fannin A, Fenge LA, Hicks C, et al. (2008) Social Work Practice with Older Lesbians and Gay Men, Exeter: Learning Matters.

Field J. (2008) Social Capital, London: Routledge.

Fisher CM, Irwin JA and Coleman JD. (2013) LGBT Health in the Midlands: A Rural/Urban Comparison of Basic Health Indicators. Journal of Homosexuality 61: 1062-1090.

Gabbay SG and Wahler JJ. (2002) Lesbian Aging. Journal of Gay \& Lesbian Social Services 14: $1-21$.

GRAI and Curtin Health Innovation Research Institute. (2010) 'We don't dave any of those type of people here': Retirement Accommodation and Aged Care Issues for NonHeterosexual Populations. Perth, WA. Available online at 
Final pre-publication version. This article is now published as: King, A and Cronin, A (2016) "Bonds, Bridges and Ties: Appling Social Capital Theory to LGBT People's Housing Concerns Later in Life", Quality in Ageing and Older Adults, 17(1): 16-25.

http://grai.org.au/wordpress/wp-content/uploads/2010/07/We-dont-have-any-of-thosepeople-here.pdf (date accessed 10/01/15).

Grossman AH, Frank JA, Graziano MJ, et al. (2014) Domestic Harm and Neglect Among Lesbian, Gay, and Bisexual Older Adults. Journal of Homosexuality 61: 1649-1666.

Guasp A. (2011) Lesbian, Gay and Bisexual People in Later Life. London: Stonewall.

Hamburger LJ. (1997) The Wisdom of Non-Heterosexually Based Senior Housing and Related Services. Journal of Gay \& Lesbian Social Services 6: 11-25.

Hinrichs KLM and Vacha-Haase T. (2010) Staff Perceptions of Same-Gender Sexual Contacts in Long-Term Care Facilities. Journal of Homosexuality 57: 776-789.

Hubbard R and Rossington J. (1995) As We Grow Older: A Study of the Housing and Support Needs of Older Lesbians and Gay Men. London: Polari. Available from URL http://www.casweb.org/polari/file-

storage/download/As\%20We\%20Grow\%20Older.pdf?version_id=66608

(Date accessed 04/02/08), 1-89.

Hughes M and Kentlyn S. (2011) Older LGBT People's Care Networks and Communities of Practice: A Brief Note. International Social Work 54: 436-444.

Jackson NC, Johnson MJ and Roberts R. (2008) The Potential Impact of Discrimination Fears of Older Gays, Lesbians, Bisexuals and Transgender Individuals Living in Small- to Moderate-Sized Cities on Long-Term Health Care. Journal of Homosexuality 54: 325-339.

Johnson AM, Jackson NC, Kenneth-Arnette J, et al. (2005) Gay and Lesbian Perceptions of Descrimination in Retirement Care Facilities. Journal of Homosexuality 49: 83-102.

Jones R. (2011) Imagining Bisexual Futures: Positive, Non-Normative Later Life. Journal of Bisexuality 11: 245-270.

King A. (2015) Prepare for Impact? Reflecting on Knowledge Exchange Work to Improve Services for Older LGBT People in Times of Austerity. Social Policy and Society 14: $15-27$.

King A. (forthcoming 2016) Older Lesbian, Gay and Bisexual Adults: Identities, Intersections and Institutions, Farnham: Ashgate.

Knochel KA, Croghan CF, Moone RP, et al. (2012) Training, Geography, and Provision of Aging Services to Lesbian, Gay, Bisexual, and Transgender Older Adults. Journal of Gerontological Social Work 55: 426-443.

Knocker S. (2006) The Whole of Me: Meeting the Needs of Older Lesbians, Gay Men and Bisexuals Living in Care Homes and Extra Care Housing. Age Concern. Available online at http://www.scie-socialcareonline.org.uk/profile.asp?guid=0b250fa8-c0e9493b-8c50-07f963114d32 (date accessed 01/08/08).

Lucco AJ. (1987) Planned Retirement Housing Preferences of Older Homosexuals. Journal of Homosexuality 14: 35-56.

Metlife. (2010) Still Out, Still Aging: TheMetLife Study of Lesbian, Gay, Bisexual, and Transgender Baby Boomers. New York: Metropolitan Life Insurance Company. Available online

at: https://www.metlife.com/assets/cao/mmi/publications/studies/2010/mmi-still-out-stillaging.pdf (date accessed 16/10/13), 1-32.

Musingarimi P. (2008) Housing Issues Affecting Older Gay, Lesbian and Bisexual People in the UK: A Policy Brief. London: International Longevity Centre.

Neville S and Henrickson M. (2010) 'Lavender retirement': A Questionnaire Survey of Lesbian, Gay and Bisexual People's Accommodation Plans for Old Age. International Journal of Nursing Practice 16: 586-594. 
Final pre-publication version. This article is now published as: King, A and Cronin, A (2016) "Bonds, Bridges and Ties: Appling Social Capital Theory to LGBT People's Housing Concerns Later in Life", Quality in Ageing and Older Adults, 17(1): 16-25.

Orel N. (2014) Investigating the Needs and Concerns of Lesbian, Gay, Bisexual, and Transgender Older Adults: The Use of Qualitative and Quantitative Methodology. Journal of Homosexuality 61: 53-78.

Phillips J and Marks G. (2006) Coming Out, Coming In: How Do Dominant Discourses Around Aged Care Facilities Take Into Account the Identities and Needs of Ageing Lesbians? Gay and Lesbian Issues and Psychology Review 2: 67-77.

Portes A. (1998) Social Capital: Its Orgins and Applications in Modern Sociology. Annual Review of Sociology 24: 1-24.

Purdie-Vaughns V and Eibach RP. (2008) Intersectional invisibility: The distinctive advantages and disadvantages of multiple subordinate-group identities. Sex Roles 59: 377-391.

Putnam RD. (1993) Making Democracy Work: Civic Traditions in Modern Italy, Princeton, NJ: Princeton University Press.

Putnam RD. (2000) Bowling Alone: The Collapse and Revival of American Community, New York: Simon and Schuster.

SAGE. (2012) Improving the Lives of Older Transgender Adults: Recommendations for Policy and Practice. New York: Services and Advocacy for GLBT Elders (SAGE). Available online at http://transequality.org/sites/default/files/docs/resources/TransAgingPolicyReportFull. pdf (date accessed 14/04/2015).

Shippy R, Cantor M and Brennan M. (2004) Social Networks of Aging Gay Men. The Journal of Men's Studies 13: 107-120.

Skeggs B. (2004) Class, Self, Culture, London: Routledge.

Stein GL, Beckerman NL and Sherman PA. (2010) Lesbian and Gay Elders and Long-Term Care: Indentifying the Unique Psychosocial Perspectives and Challlenges. Journal of Gerontological Social Work 53: 421-435.

Stone AL and Ward J. (2011) From 'Black People are Not a Homosexual Act' to 'Gay is the New Black': Mapping White Uses of Blackness in Modern Gay Rights Campaigns in the United States. Social Identities: Journal for the Study of Race, Nation and Culture 17: 605-624.

Sullivan KM. (2013) Acceptance in the Domestic Environment: The Experience of Senior Housing for Lesbian, Gay, Bisexual, and Transgender Seniors. Journal of Gerontological Social Work 57: 235-250.

Tolley C and Ranzijn R. (2006) Heteronormativity Amongst Staff of Residential Care Facilities. Gay and Lesbian Issues and Psychology Review 2: 78-86.

Traies J. (2012) 'Women Like That': Older Lesbians in the UK. In: Ward R, Rivers I and Sutherland M (eds) Lesbian, Gay, Bisexual and Transgender Ageing: Biographical Approaches for Inclusive Care and Support. London: Jessica Kingsley Publishers 6782.

Vaccaro A. (2009) Intergenerational Perceptions, Similarities and Differences: A Comparative Analysis of Lesbian, Gay, and Bisexual Millennial Youth with Generation X and Baby Boomers. Journal of LGBT Youth 6: 113-134.

Westwood S. (2013) 'My Friends are My Family': an argument about the limitations of contemporary law's recognition of relationships in later life. Journal of Social Welfare and Family Law 35: 347-363.

Westwood S. (2015) 'We see it as being heterosexualised, being put into a care home': gender, sexuality and housing/care preferences among older LGB individuals in the UK. Health \& Social Care in the Community onlinefirst. : n/a-n/a. 
Final pre-publication version. This article is now published as: King, A and Cronin, A (2016) "Bonds, Bridges and Ties: Appling Social Capital Theory to LGBT People's Housing Concerns Later in Life", Quality in Ageing and Older Adults, 17(1): 16-25.

Witten TM. (2009) Graceful Exits: Intersection of Aging, Transgender Identities, and the Family/Community. Journal of GLBT Family Studies 5: 35-61.

Witten TM. (2014) It's Not All Darkness: Robustness, Resilience, and Successful Transgender Aging. LGBT Health 1: 24-33.

\footnotetext{
${ }^{\mathrm{i}}$ We have critically engaged with such acronyms elsewhere and are aware that they can obscure diversity, difference and intersectionality (see AUTHOR B \& A) We use them here as an example of intercategorical intersectionality: recognising difference but used as a point of comparison to other social groups, particularly those that conform to heterosexual and cisgender norms

${ }^{\text {ii }}$ Here we draw on our use of SCT as outlined in Cronin, A, and A King. 2014. "Only Connect? Lesbian, Gay and Bisexual (LGB) Adults and Social Capital." Ageing and Society no. 34 (2):258-279. But here extending it, for the first time in studies of LGBT ageing, to questions of housing.
} 